\title{
Exploring of Hidden Anaemia among Asymptomatic Women in a Unique Health Check-up Institute, Ningen Dock in Japan
}

\author{
Rie Kitayama ${ }^{1}$, Eriko Hosokawa ${ }^{1}$, Chiaki Morioka ${ }^{1}$, Satoshi Ichigo ${ }^{2}$ and Atsushi Imai ${ }^{2 *}$ \\ ${ }^{1}$ Ningen Dock Division, Matsunami General Hospital, Japan \\ ${ }^{2}$ Department of Obstetrics and Gynaecology, Matsunami General Hospital, Japan
}

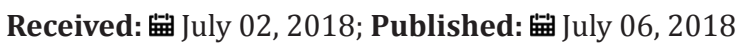

*Corresponding author: Atsushi Imai, Institute of Endocrine-related Cancer, Matsunami General Hospital, Kasamatsu, Gifu 501-6062 Japan

\begin{abstract}
In Japan, there are unique facilities (namely Ningen Dock) of health check-up provide seemingly healthy participants a health examination including health and cancer screening activities at their own expense. The most advanced examination equipment and examinations do not only provide high accuracy but they also reduce stress on the body of a participant. Using the medical equipment and diagnostic techniques allows for successful detection of many diseases while in early stages development. This early detection of masked critical problems leads to quicker response to disease. This communication evaluated an assure role of Ningen Dock in evaluation of hidden anaemia among asymptomatic women. In participants with haemoglobin $(\mathrm{Hb})$ level $<10.0 \mathrm{~g} / \mathrm{dl}$, the percent of women who experienced dyspnoea, weakness, constipation and fatigue is significantly higher than in other two groups. The mean number of persons with menopause, hyper menorrhea and irregular bleeding were significantly correlated with the group with $\mathrm{Hb}$ level $<10.0 \mathrm{~g} / \mathrm{dl}$. We recommend a thorough uterus and reproductive work-up by gynaecologist for any women with $\mathrm{Hb}$ level $<10.0 \mathrm{~g} / \mathrm{dl}$.
\end{abstract}

Keywords: Health Check-Up; Ningen Dock; Hidden Anaemia; Attitude Toward Screening; Cancer Screening Activities; CT Scans, MRI Scans; Asymptomatic Women; Matsunami; Hyper Menorrhea

\section{Introduction}

Anaemia is a significant public health concern that affects approximately $20 \%$ of the global population. Women of reproductive age are at an increased risk of anaemia [1-3]. That condition reduces physical work capacity but there are, at present, no recommendations for routine anaemia check-up of nonpregnant and well-being women [4], although anaemic screening is a relatively simple, low cost and non-invasive method. In Japan, there are unique facilities (namely Ningen Dock) of health checkup provide seemingly healthy participants a health examination including cancer screening activities at their own expense [5]. Japan is indeed the most advanced medical devices country in the world. For example, about half of the CT scans and about 1/3 of the MRI scans are owned by medical facilities in Japan. The most advanced examination equipment and examinations do not only provide high accuracy but they also reduce stress on the body of a participant. Using these medical equipments and diagnostic techniques allows for accurate detection of certain diseases while in early stages development. This early detection leads to quicker response to disease. These situations prompted us to evaluate a significant role of Ningen Dock in exploring hidden anaemia even of asymptomatic women.

\section{Materials and Methods}

Between April 2016 and March 2017, 3,385 asymptomatic women, age 18-85, visited the Ningen Dock in Matsunami General Hospital for their general health check-up. All participants underwent medical evaluations including a medical history, physical examination, blood sampling, and urine sampling and radiological imaging as part of a routine health check-up and cancer screening [6]. Using univariate analysis, anaemia prevalence was compared by background characteristics, reproductive variables and lifestyle characteristics. This study was approved by the institutional review board at Matsunami General Hospital, and the need for informed consent was waived. Data and statistical analyses were done with IBM SPSS Statistics 24. For all the statistical tests, level of significance $\mathrm{P}<0.05$ was considered.

\section{Results}

Table 1 shows the distribution of haemoglobin ( $\mathrm{Hb}$ ) levels status by various study characteristics and general condition concerns. We found significant $(\mathrm{P}<0.05)$ variation in reproductive variables (menopause, hyper menorrhea and irregular bleeding) and lifestyle characteristics (unbalanced diet and fast walking speed) among $\mathrm{Hb}$ 
levels status. In participants with $\mathrm{Hb}$ level $<10.0 \mathrm{~g} / \mathrm{dl}$, the percent of women who experienced dyspnoea, weakness, constipation and fatigue is significantly higher than in other two groups. The mean number of persons with menopause, hyper menorrhea and irregular bleeding were significantly correlated with the group with $\mathrm{Hb}$ level $<10.0 \mathrm{~g} / \mathrm{dl}$.

Table 1: Distribution of female participants by study characteristics and hemoglobin level status Between April 2006 and March 2017, 3,385 asymptomatic women, age 18-85, visited the Ningen Dock in Matsunami General Hospital for their general health check-up. $\mathrm{BMI}$, body mass index MCV, mean corpuscular volume; TG, triglyceride; LDL, low density lipoprotein-cholesterol. * $\mathrm{P}<0.05$. The lowest hemoglobin level was $5.9 \mathrm{~g} / \mathrm{dl}$.

\begin{tabular}{|c|c|c|c|}
\hline \multirow[b]{2}{*}{ Variables } & \multicolumn{3}{|c|}{ Hemoglobin levels (g/dl) } \\
\hline & $<10.0(\mathrm{n}=149)^{\mathrm{a}}$ & $10.1-11.0(n=180)$ & $11.1<(n=3,056)$ \\
\hline Age in years & $44.4 \pm 6.1$ & $45.2 \pm 7.9$ & $48.0 \pm 10.8$ \\
\hline BMI $\left(\mathrm{kg} / \mathrm{m}^{2}\right)$ & $21.7 \pm 3.2$ & $21.4 \pm 3.7$ & $21.6 \pm 3.6$ \\
\hline Blood pressure (mmHg) & $114 \pm 8 / 69 \pm 8$ & $115 \pm 16 / 70 \pm 11$ & $118 \pm / 73 \pm 11$ \\
\hline $\operatorname{MCV}(\mathrm{fl})$ & $72.2 \pm 7.0^{*}$ & $81.1 \pm 6.8$ & $88.8 \pm 4.2$ \\
\hline Platelets $\left(\mathrm{x} 10^{4} / \mu \mathrm{l}\right)$ & $31.5 \pm 8.3^{*}$ & $26.3 \pm 6.3$ & $22.5 \pm 5.2$ \\
\hline $\mathrm{TG}(\mathrm{mg} / \mathrm{dl})$ & $69 \pm 37$ & $74 \pm 38$ & $83 \pm 47$ \\
\hline $\operatorname{LDL}(\mathrm{mg} / \mathrm{dl})$ & $106 \pm 26$ & $114 \pm 27$ & $119 \pm 30$ \\
\hline Albumin & $4.28 \pm 0.20$ & $4.32 \pm 0.24$ & $4.43 \pm 0.23$ \\
\hline HbA1c (\%) & $5.5 \pm 0.3$ & $5.5 \pm 0.3$ & $5.5 \pm 0.5$ \\
\hline Palpitation & $9.4 \%$ & $8.3 \%$ & $7.8 \%$ \\
\hline Dyspnea & $8.1 \% *$ & $5.6 \%$ & $3.5 \%$ \\
\hline Weakness & $22.1 \% *$ & $18.3 \%$ & $9.4 \%$ \\
\hline Constipation & $28.9 \% *$ & $23.9 \%$ & $19.5 \%$ \\
\hline Fatigue & $23.5 \% *$ & $27.8 \%$ & $18.4 \%$ \\
\hline Unbalanced diet & $38.5 \% *$ & $40.0 \%$ & $31.5 \%$ \\
\hline Menopause & $4.1 \% *$ & $13.2 \%$ & $41.8 \%$ \\
\hline Hypermenorrhea & $36.2 \% *$ & $25.2 \%$ & $11.2 \%$ \\
\hline Irregular bleeding & $14.1 \% *$ & $7.3 \%$ & $4.5 \%$ \\
\hline Diet & $13.5 \% *$ & $19.9 \%$ & $22.8 \%$ \\
\hline Fast walking speed & $26.4 \% *$ & $36.4 \%$ & $46.0 \%$ \\
\hline Anemic therapy experience & $52.3 \% *$ & $37.2 \%$ & $11.9 \%$ \\
\hline
\end{tabular}

\section{Discussion}

Low $\mathrm{Hb}$ level is an alarm sign that needs to evaluate for its etiology and must be appreciated for both its primary medical impact on the patient and it's secondary impact on the patient's co morbidities [1,7]. The present communication found the extremely assure role of Ningen Dock to screen the hidden anaemia in asymptomatic women. Our observation supports the idea of significant variation in reproductive variables and lifestyle characteristics among haemoglobin ( $\mathrm{Hb}$ ) levels status. This finding may recommend a thorough myoma and reproductive work-up by gynaecologist for any women with Hb level $<10.0 \mathrm{~g} / \mathrm{dl}$. Women's attitudes and beliefs related to screening frequency may differ if they reflected truly informed preference and may be related to less screening. Not paying attention to health screening is risk factors for non-attendance to health check-up [6].

The most important risk factor for non-attendance to health check-up includes not paying attention to health screening. Ningen Dock check-ups provide an occasion to realize preventive medicine. An important aim of health check-up is to provide support to improving risk factors that accelerate the risk of outbreak of a critical disease at an early stage, before subjective symptoms become apparent. Additionally, meticulous educational guidance is provided to match individual living patterns, education level and ways of thinking. Ningen Dock can also conceive of a time in the future when more appropriate and effective educational advice could be continuously provided according to a participant cultural background and lifestyle habits, via collaboration with health-related public services. The present data is from subject to the limitations of any analysis of self-covered health check-up survey data from participants in a Ningen Dock in Japan. Although data are weighted to reflect the Japanese population, the extent to which results are generalizable is not known. Other and larger studies extended to non-Asian should attempt to oversample racial minorities and include a detailed assessment of whole body disease screening history and follow-up treatment.

\section{Author's contribution}

RK managed all data and performed the analyses. AI designed the study and drafted the manuscript. All authors participated general examinations in Ningen Dock and commented on various drafts and approved the final version of the manuscript. 


\section{References}

1. Freeman A, Morando D (2018) Anemia, Screening. StatPearls [Internet] Treasure Island (FL)

2. Wilunda C, Massawe S, Jackson C (2013) Determinants of moderate-tosevere anaemia among women of reproductive age in Tanzania: analysis of data from the 2010 Tanzania Demographic and Health Survey. Trop Med Int Health 18(12): 1488-1497.

3. Nguyen P, Gonzalez Casanova I, Nguyen H, Pham H, Truong T, Nguyen S, et al. (2015) Multicausal etiology of anemia among women of reproductive age in Vietnam. Eur J Clin Nutr 69(1): 107-113.

4. Bharati P, Som S, Chakrabarty S, Bharati S, Pal M (2008) Prevalence of anemia and its determinants among nonpregnant and pregnant women in India. Asia Pac J Public Health 20(4): 347-459.

\section{ISSN: 2574-1241}

DOI: 10.26717/BJSTR.2018.06.001353

Atsushi Imai. Biomed J Sci \& Tech Res

(C) This work is licensed under Creative

Submission Link: https://biomedres.us/submit-manuscript.php
5. Hinohara S (2015) Automated multiphasic health testing and services and Ningen Dock in Japan. Ningen Dock International 2: 61-64.

6. Imai A, Kajikawa H, Koiwai C, Ichigo S, Takagi H (2018) Greatrole in gynecological cancer prophylaxis of a unique health check-up institute, Ningen Dock in Japan. In R Rajkumar (Eds.), Cervical cancer: screening, treatment and prevention, Intech, Croatia pp: 45-55.

7. Yokoi K, Konomi A (2017) Iron deficiency without anaemia is a potential cause of fatigue: meta-analyses of randomised controlled trials and cross-sectional studies. Br J Nutr 117(10):1422-1431.

Assets of Publishing with us
BIOMEDICAL
RESEARCHES

